\title{
Predicting Feed Intake of the Individual Dairy Cow
}

\author{
I. Halachmi, ${ }^{1}$ Y. Edan, ${ }^{2}$ U. Moallem, ${ }^{1}$ and E. Maltz ${ }^{1}$ \\ ${ }^{1}$ Agricultural Research Organization (A.R.O.), Ministry of Agriculture and Rural Development, \\ the Volcani Center, P. O. Box 6, Bet Dagan 50250, Israel \\ ${ }^{2}$ Department of Industrial Engineering and Management, \\ Ben-Gurion University of the Negev, Beer Sheva 84105, Israel
}

\section{ABSTRACT}

The voluntary feed intake of the dairy cow is an important variable in dairy operation but is impossible to measure individually when cows are kept in groups or grazing. Existing formulas that calculate dry matter intake (DMI) from ration and performance variables are not applicable to an individual cow for online decision-making, such as daily ration density adjustment by computerized feeders in a milking robot. This led to a new DMI modeling approach of using only animal factors that are measurable online on an individual basis. In 1997 we published a small-scale attempt of this approach using milk yield (MY) and body weight (BW). In 2001, this approach was adopted by the National Research Council (NRC), using 4\% fat-corrected milk rather than MY together with $\mathrm{BW}$ and time after calving. In the present study, we increased the number of cows. The model is a multiple regression, where the descriptive variables are the interrelation MY/BW, daily BW change, and milk fat including the effect of previous $2 \mathrm{~d}$. The coefficients are calculated on daily basis, i.e., each day has its own coefficients. Our model differs from that of the NRC by: 1) the descriptive variable, 2) using daily coefficients to deal with the everchanging physiological state of lactation, and 3) considering previous performance. Two data sets (60 cows together) acquired in 2 intervals of the Volcani Center herd were used to calibrate (18 cows) and test (42 cows) the model. Model validity was statistically tested, compared to that of the NRC, and was not rejected with $99.5 \%$ confidence.

(Key words: dry matter intake model, milking robot, dairy cow, feed ration)

Abbreviation key: $\mathbf{M Y}=$ daily milk yield, $\mathbf{R M B}=$ robotic milking barn.

Received May 8, 2003.

Accepted December 2, 2003.

Corresponding author: I. Halachmi; e-mail: halachmi@volcani. agri.gov.il.

\section{INTRODUCTION}

The voluntary feed intake or DMI of the dairy cow is an important variable in dairy management; it facilitates the nutritionally and economically accurate formulation of rations. Together with milk yield it can be used to estimate the economic value of an individual cow at any given stage of lactation, and hence to improve the economic decisions of the whole operation. This variable becomes crucial for nutritional reasons, when concentrates are allocated individually through computer-controlled self-feeders. In robot-milking dairies, unlike conventional dairies, these self-feeders are an essential part of the robot-milking system (Devir et al., 1993, 1997; Spahr and Maltz, 1997; KetelaarDe Lauwere et al., 1999; Halachmi et al., 1998b, 2001, 2002; Halachmi, 2000, 2004; Hogeveen et al., 2002; Maltz et al., 2002).

Individual DMI measurements are practicable in tie-stall barns or in small-scale operations (Halachmi et al., 1998a). Otherwise, DMI can be measured only by weighing mixer wagons for a group of cows. On a large scale, individual DMI can be evaluated only by modeling, based on measurable variables that are known to affect it (see list of variables below and NRC, 2001). The great variety of variables and local effects led scientists to select "only animal factors, which would be easily measured or known" (NRC, 2001).

There are several approaches to modeling DMI, including mathematical models of ruminal function (Mertens, 1987); the weekly average intake of a group (Roseler et al., 1997a, 1997b) or the daily intake of an individual cow (Halachmi et al., 1997). It is generally accepted that short-term (daily) individual DMI evaluation requires a sacrifice of model accuracy, and that during a time of transition (late dry period and early lactation), DMI can hardly be evaluated (Roseler et al., 1997b), and models have to be specially adjusted (Roseler et al., 1997b; NRC, 2001). Nevertheless, success in small-scale attempts suggested that DMI modeling for individual cows on a daily basis, and even in transition time is feasible (Halachmi et al., 1997); it could be done by using absolute values (NRC, 2001), 
as well as day-to-day fluctuations in BW (Maltz and Metz, 1994; Maltz et al., 1997) and milk yield.

Therefore, the purpose of the present study was to set up a model to calculate DMI from available daily milk yield (MY) and BW data acquired by off-the-shelf sensors, and periodical information on milk composition. The model calculates DMI any given day throughout lactation by using the absolute values of MY and BW as well as the relative values of their daily fluctuations, and "historic" information.

\section{MATERIALS AND METHODS}

\section{Animal Nutrition and Husbandry}

Sixty cows participated in the research. The daily intake, BW, and MY of each cow were recorded during $1 \mathrm{yr}$ from parturition. It results in $18,000 \mathrm{~d}$ of cow individual data. The first 39 high-yielding multiparous Israeli-Holstein cows calved between November 1996 and February 1997. An identical measurement procedure was executed during 2001, this time with 21 cows. The cows were housed in loose-covered pens with adjacent yards at the Bet Dagan experimental farm. Average daily winter temperatures ranging 6.6 to $24.2^{\circ} \mathrm{C}$ with 50 to $80 \%$ relative humidity, and 11 and 13 light and dark hours, respectively, and summer temperatures 13.6 to $30.9^{\circ} \mathrm{C}$ with 54 to $76 \%$ relative humidity, and 14 and 10 light and dark hours, respectively. The cows were offered a TMR containing corn grain, barley grain, sorghum grain, wheat silage, corn silage, and wheat bran; the nutrients were $\mathrm{NE}_{\mathrm{L}}$ of $1.67 \mathrm{Mcal} / \mathrm{kg}$, $\mathrm{CP} 16.9 \%$, ADF $18.8 \%$, NDF $34.2 \%$, $\mathrm{P} 0.5 \%$, and $\mathrm{Ca}$ $0.8 \%$ of DM-a common Israeli diet, described by Moallem et al. (2000). All feeds were mixed and fed once daily from a mixing wagon. Each cow was fed from an individual trough, 1-m width in a specific position; the system provided free and easy entry to the trough and ad libitum feed consumption for each individual cow kept in the group. The duration and feed intake at every visit were recorded by a 'real-time control system for individual dairy cow food intake' as previously described by Halachmi et al. (1998a). All cows were adapted to the feeding system for 2 wk during the dry period. Orts were weighed automatically and removed daily at 9 a.m. The intake of the previous day was determined and 107 to $110 \%$ of DMI was offered in every individual box at 10 a.m. Samples of feeds and orts were analyzed weekly for each group of cows. The cows were weighed with an automatic electronic scale 3 times daily after every milking at 0700,1400 , and $2100 \mathrm{~h}$. Cows were milked 3 times daily, and their MY were recorded electronically. Milk composition from a composite of 3 consecutive milkings was determined every 2 wk for $150 \mathrm{~d}$ and then monthly until the end of lactation.

\section{Model Development}

The model was developed in 2 steps. 1) Step-wise regression analysis, which attempts to quantify the effects of independent variables on the DMI to be forecasted. 2) Varying regression coefficients in the course of the lactation period, i.e., regression coefficients were calculated for each day along the lactation period.

1) The independent variables that were analyzed by the stepwise and cross correlation procedures were:

a. Milk yield (kg) of the current day, and up to 14 $\mathrm{d}$ back, the peak MY, daily difference from peak MY, and MY moving average of 3, 7, and $10 \mathrm{~d}$.

b. Body weight $(\mathrm{kg})$ of the current day, and up to $14 \mathrm{~d}$ back, the trough BW, daily difference from trough BW, and moving average of 3,7 , and $10 \mathrm{~d}$.

c. The ratio milk yield to $\mathrm{BW}$ and all the interrelations of the above (a) and (b).

d. Milk fat, protein, and lactose (once a month measurement).

e. Body condition (once a week evaluation by the same person, on a 1 (very thin) to 5 (obese) scale.

f. $4 \%$ FCM (kg) of the current day, and up to $14 \mathrm{~d}$ back, the peak FCM, daily difference from peak FCM, and moving average of 3,7 , and $10 \mathrm{~d}$.

All variables that had a relatively low contribution to the $\mathrm{R}^{2}$ were excluded. We found that the interrelationships among the "independent" variables contribute more than their absolute values (see Discussion and Table 1). Periodical milk fat was included in the model despite its low contribution, since online fat sensor is intensively under development (Schmilovitch et al., 2000). Once this factor is available on a daily basis, its contribution to the DMI model will most likely be very significant (see Discussion).

2) Our multiple regressions can be represented by the following matrix expression-so-called 'Predicting model':

$$
\begin{gathered}
D M I_{0, i}=\mathrm{b}_{0, i}+\mathrm{b}_{1, i} \frac{M Y_{0}}{B W_{0}}+\mathrm{b}_{2, i} \frac{M Y_{-1}}{B W_{-1}} \\
+\mathrm{b}_{3, i} \frac{M Y_{-2}}{B W_{-2}}+\mathrm{b}_{4, i} B W_{0}+\mathrm{b}_{5, i} \frac{B W_{-1}}{B W_{0}} \\
+\mathrm{b}_{6, i} f a t+e,
\end{gathered}
$$


Table 1. Cross correlation matrix of animal-related variables that were used in our and NRC models; average throughout the lactation period.

\begin{tabular}{|c|c|c|c|c|c|c|c|c|c|c|c|c|}
\hline & $\mathrm{DMI}^{2}$ & $\begin{array}{l}1^{1} \\
\mathrm{MY}_{0} / \\
\mathrm{BW}_{0}\end{array}$ & $\begin{array}{l}2 \\
\mathrm{MY}_{-1} / \\
\mathrm{BW}_{-1}\end{array}$ & $\begin{array}{l}3 \\
\mathrm{MY}_{-2} / \\
\mathrm{BW}_{-2}\end{array}$ & $\mathrm{BW}_{0}$ & $\begin{array}{l}5 \\
\mathrm{BW}_{-1} / \\
\mathrm{BW}_{0}\end{array}$ & fat & $\mathrm{MY}_{0}$ & $\mathrm{MY}_{-1}$ & $\mathrm{MY}_{-2}$ & $\mathrm{BW}_{0}^{0.75}$ & FCM \\
\hline & 1 & 0.44 & 0.43 & 0.42 & -0.36 & 0.04 & -0.01 & 0.3 & 029 & 0.28 & -0.35 & 0.33 \\
\hline 1 & 0.4 & 1 & 0.8 & .87 & & & & & & & & 0.86 \\
\hline 2 & 0.43 & 0.88 & 1 & 0.88 & -0 & -0. & & 0. & 0. & 0.76 & & 0.73 \\
\hline 3 & 0.4 & 0.8 & & 1 & -0.37 & 0 & & 0. & 0. & 0.8 & -0.3 & 0.73 \\
\hline 4 & -0.36 & -0.38 & -0.37 & -0.37 & 1 & -0.1 & -0.34 & 0.0 & 0. & 0.08 & 1 & -0.06 \\
\hline 5 & 0.04 & 0.04 & -0.04 & 0 & -0.1 & 1 & 0 & -0.01 & 0.01 & 0.01 & -0.1 & -0.01 \\
\hline 6 & -0.01 & -0.22 & -0.22 & -0.22 & -0.34 & 0 & 1 & -0.41 & -0.41 & -0.41 & -0.34 & -0.02 \\
\hline 7 & 0.3 & & & 0.75 & & -0.01 & & 1 & 0.87 & & & 0.91 \\
\hline 8 & $0.2 s$ & & & 0 & & & & 0. & 1 & 0.87 & & 0.77 \\
\hline$y$ & 0.28 & & & & 0.0 & & & & 0. & 1 & 0.09 & 0.76 \\
\hline 10 & -0.35 & -0.38 & -0.37 & -0.37 & 1 & -0.1 & -0.34 & $0 .($ & 0.08 & 0.09 & 1 & -0.06 \\
\hline 11 & 0.33 & 0.86 & 0.73 & 0.73 & -0.06 & -0.01 & -0.02 & 0.91 & 0.77 & 0.76 & -0.06 & 1 \\
\hline
\end{tabular}

${ }^{1}$ Variables 1 to 6 are included in our model. Variables 7 to 9 came close but were not included in the model, and variables 10 to 11 are included in the NRC model.

${ }^{2} \mathrm{DMI}$ is the forecast voluntary DMI for the individual cow as percentage of $\mathrm{BW}_{0} \cdot \mathrm{MY}_{0} / \mathrm{BW}_{0}$ is the current day's (d 0) milk yield (kg) multiplied by 100 divided by the cow's $\mathrm{BW}(\mathrm{kg})$. $\mathrm{MY}_{-1} / \mathrm{BW}_{-1}$ is the previous day's $(\mathrm{d}-1)$ milk yield $(\mathrm{kg})$ multiplied by 100 divided by the cow's $\mathrm{BW}(\mathrm{kg})$. $\mathrm{MY}_{-2} / \mathrm{BW}_{-2}$ is the milk yield that was measured $2 \mathrm{~d}$ earlier ( $\mathrm{d}-2$ ) multiplied by 100 , divided by the cow's BW. $\mathrm{BW}_{0}$ is the current $\mathrm{BW}(\mathrm{d} 0)$ divided by $100 . \mathrm{BW}_{-1} / \mathrm{BW}_{0}$ is the daily $\mathrm{BW}$ change since the previous day. Fat is the percentage of milk fat as measured in the last milk recording. $\mathrm{MY}_{0}$ is the milk yield $(\mathrm{kg})$ of the current day, $\mathrm{MY}_{-1}$ is the milk yield $(\mathrm{kg})$ of the previous day, $\mathrm{MY}_{-2}$ is the milk yield $(\mathrm{kg})$ of $2 \mathrm{~d}$ previously, FCM is the $4 \%$ FCM milk yield according to the NRC (2001) formula.

$i=3$ to $n$ days post calving where the ith subscripts are the days in lactation and the column vectors are:

$\mathrm{DMI}$ is the forecast voluntary DMI for the individual cow as percentage of $\mathrm{BW}_{0}$, i.e., $\mathrm{DMI}=100 \times$ feed intake in kilogram of $\mathrm{DM} / \mathrm{BW}_{0}$.

$\mathrm{MY}_{0} / \mathrm{BW}_{0}$ is the current day's (d 0) milk yield (kg) divided by the cow's BW $(\mathrm{kg})$,

$\mathrm{MY}_{-1} / \mathrm{BW}_{-1}$ is the previous day's $(\mathrm{d}-1)$ milk yield (kg) divided by the cow's BW $(\mathrm{kg})$,

$\mathrm{MY}_{-2} / \mathrm{BW}_{-2}$ is the milk yield that was measured $2 \mathrm{~d}$ earlier $(\mathrm{d}-2)$, divided by the cow's BW,

$\mathrm{BW}_{0}$ is the current $\mathrm{BW}(\mathrm{d} 0)$,

$\mathrm{BW}_{-1} / \mathrm{BW}_{0}$ is the daily $\mathrm{BW}$ change since yesterday, fat is the percentage of milk fat as measured in the last milk recording, $\mathrm{b}$ is the regression coefficients matrix that were calculated for each day, and e is the residual error.

The data sets of the first 18 cows with complete lactation periods were used for calculating the coefficients. Each day has its own 7 regression coefficients. An example of one day is presented in Table 2, and the entire time pattern is given in Figures 1 to 3 . Adding additional cows in the calibration data set did not improve model performance. To prevent an incorrect computer round-off, the small ratios (MYi/BWi) were multiplied by 100 , and the BW was divided by 100. The model applies information from successive 3 $\mathrm{d}$. Therefore, it starts predicting from d 3 or as soon as there is data from 3 successive days. The average correlation coefficients of the DMI of all the days were $0.44,0.43,0.42,-0.36,0.04$, and -0.01 with the chosen regression parameters: $\mathrm{MY}_{0} / \mathrm{BW}_{0}, \mathrm{MY}_{-1} / \mathrm{BW}_{-1}, \mathrm{MY}_{-2} /$ $\mathrm{BW}_{-2}, \mathrm{BW} 0, \mathrm{BW}_{-1} / \mathrm{BW}_{0}$, and Fat, respectively. The cross-correlations (Table 1) suggested that milk yield (my_0n, my_1n, my_2n,) divided by BW has higher significant value $(0.44,0.43,0.42)$ than either FCM (0.33) or milk yield absolute values $(0.30,0.29,0.28)$. Body weight as such and $\mathrm{BW}^{0.75}$ have comparable significant $(-0.36$ vs. -0.35$)$ and their contribution overlaps each other (' 1 ' in row 5 column 11 ). The new model applies different regression coefficients for every day along the lactation period. Time pattern of correlation coefficients along the lactation period is presented in Figures 4 to 5 .

\section{Model Validation}

(1) Statistical validation. Validation determines whether the mathematical model is an accurate representation of the real system. One way to validate is to compare data on the real and predicted systems (Kleijnen, 1987). We applied the following stringent validation requirements: the model is valid if and only if the real and the predicted values have (i) identical means, (ii) identical variance, and (iii) positively correlated real and model responses. The corresponding statistical testing was applied in the form of Kleijnen's $F$-test which in our opinion is the proper statistical 
Table 2. Correlation and regression coefficients of animal-related variables that were used for modeling daily DMI in a typical day (20).

\begin{tabular}{|c|c|c|c|c|}
\hline \multirow[b]{2}{*}{ Variables $^{1}$} & \multirow{2}{*}{$\begin{array}{l}\text { Correlation } \\
\text { coefficients }\end{array}$} & \multicolumn{2}{|c|}{ Confidence interval } & \multirow{2}{*}{$\begin{array}{l}\text { Regression } \\
\text { coefficients }\end{array}$} \\
\hline & & Lower & Upper & \\
\hline \multirow{8}{*}{$\begin{array}{l}\mathrm{MY}_{0} / \mathrm{BW}_{0} \\
\mathrm{MY}_{-1} / \mathrm{BW}_{-1} \\
\mathrm{MY}_{-2} / \mathrm{BW}_{-2} \\
\mathrm{BW}_{0} \\
\mathrm{BW}_{-1} / \mathrm{BW}_{0} \\
\text { Fat } \\
\text { Intercept }\end{array}$} & 0.57 & -0.38 & 1.06 & 0.34 \\
\hline & 0.71 & -1.50 & 0.51 & -0.49 \\
\hline & 0.64 & -0.61 & 1.36 & 0.37 \\
\hline & -0.58 & -1.17 & 0.56 & -0.30 \\
\hline & 0.08 & -41.85 & 4.14 & -18.86 \\
\hline & -0.16 & -1.04 & 0.54 & -0.25 \\
\hline & & & & 23.52 \\
\hline & $\mathrm{R}^{2} 0.73$ & F-value 5.41 & $P$-valu & \\
\hline
\end{tabular}

\footnotetext{
${ }^{1} \mathrm{MY}_{0} / \mathrm{BW}_{0}$ is the current day's (d 0) milk yield $(\mathrm{kg})$ multiplied by 100 divided by the cow's BW (kg). MY ${ }_{1} / \mathrm{BW}_{-1}$ is the previous day's $(\mathrm{d}-1)$ milk yield $(\mathrm{kg})$ multiplied by 100 divided by the cow's $\mathrm{BW}(\mathrm{kg})$. $\mathrm{MY}_{-2} /$ $\mathrm{BW}_{-2}$ is the milk yield that was measured $2 \mathrm{~d}$ earlier $(\mathrm{d}-2)$ multiplied by 100 , divided by the cow's BW. $\mathrm{BW}_{0}$ is the current $\mathrm{BW}(\mathrm{d} 0)$ divided by $100 . \mathrm{BW}_{-1} / \mathrm{BW}_{0}$ is the daily $\mathrm{BW}$ change since the previous day. Fat is the percentage of milk fat as measured in the last milk recording. Therefore, the dependent variable on d 20, the forecast voluntary dry matter intake for the individual cow as percentage of $\mathrm{BW}_{0}$ is: $D M I_{0,20}=23.52+0.34 \frac{M Y_{0}}{B W_{0}}-0.49 \frac{M Y_{-1}}{B W_{-1}}+0.37 \frac{M Y_{-2}}{B W_{-2}}-0.30 B W_{0}-18.86 \frac{B W_{-1}}{B W_{0}}-0.25$ fat the feed intake in kilograms of $\mathrm{DM}$ per the specific cow on d $20=\mathrm{BW}_{0} \times D M I_{0,20} / 100$.
}
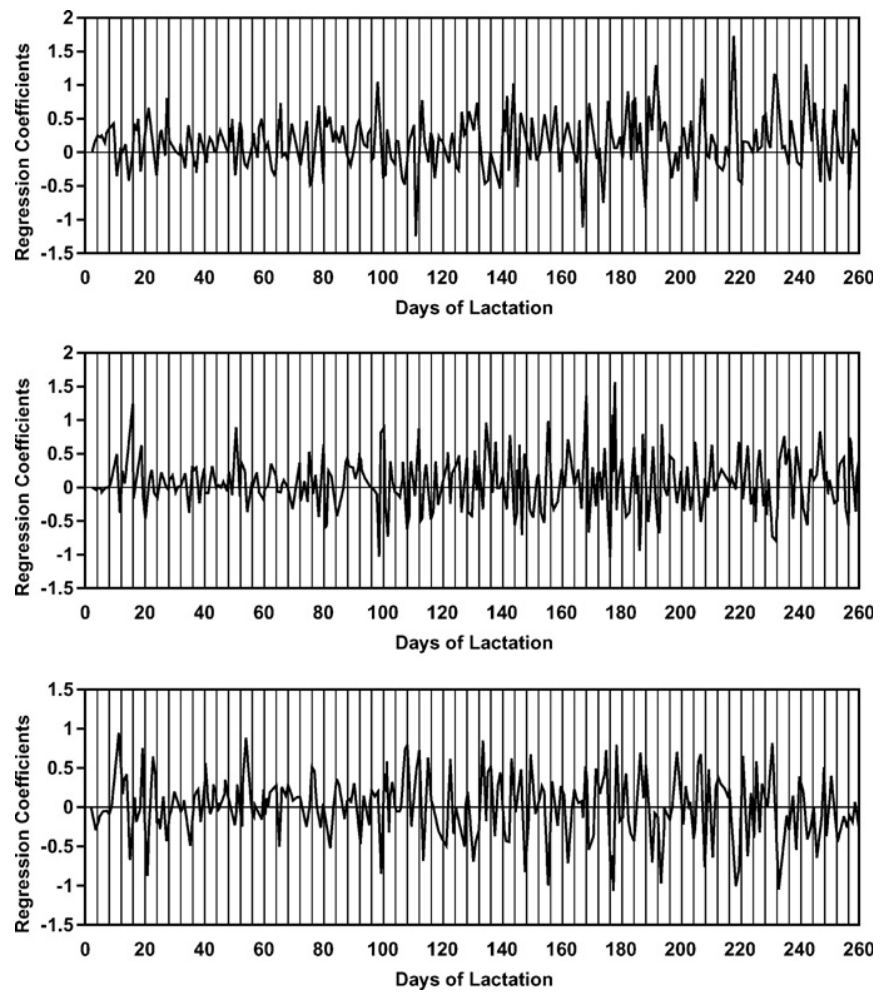

Figure 1. Regression coefficients' values throughout the lactation period. Top panel; the ratio of current day milk yield to current day body weight multiplied by 100 (so called $\mathrm{MY}_{0} / \mathrm{BW}_{0}$ ), middle panel; the ratio of previous days' milk yield to previous days' body weight multiplied by 100 (so called $\mathrm{MY}_{-1} / \mathrm{BW}_{-1}$ ), lower panel; the ratio of 2 $\mathrm{d}$ ago milk yield to $2 \mathrm{~d}$ ago body weight multiplied by 100 (so called $\mathrm{MY}_{-2} / \mathrm{BW}_{-2}$ ). test for a model like ours (Kleijnen et al., 1998), as follows: Let $\mathrm{X}_{\mathrm{i}}$ and $\mathrm{Y}_{\mathrm{i}}$ denote the real and modeled outputs, respectively, in observation $\mathrm{i}$; the real system and the model should yield the same mean, the same variance, and positively correlated responses. Calculate the sums $Q_{i}=X_{i}+Y_{i}$, the differences $D i=X_{i}-Y_{i}$, and the regression $\mathrm{E}(\mathrm{D} \mid \mathrm{Q}=\mathrm{q})=\gamma_{0}+\gamma_{1} \mathrm{q}$. If $\mathrm{X}$ and $\mathrm{Y}$ have a common mean, that implies that $\mathrm{E}(\mathrm{D})=0$; it can be proven (Kleijnen et al., 1998) that common variances imply zero correlation between $\mathrm{D}$ and $\mathrm{Q}$; together this gives $\left(\mathrm{H}_{0}:\right) \gamma_{0}=0$ and $\gamma_{1}=0$. Therefore,
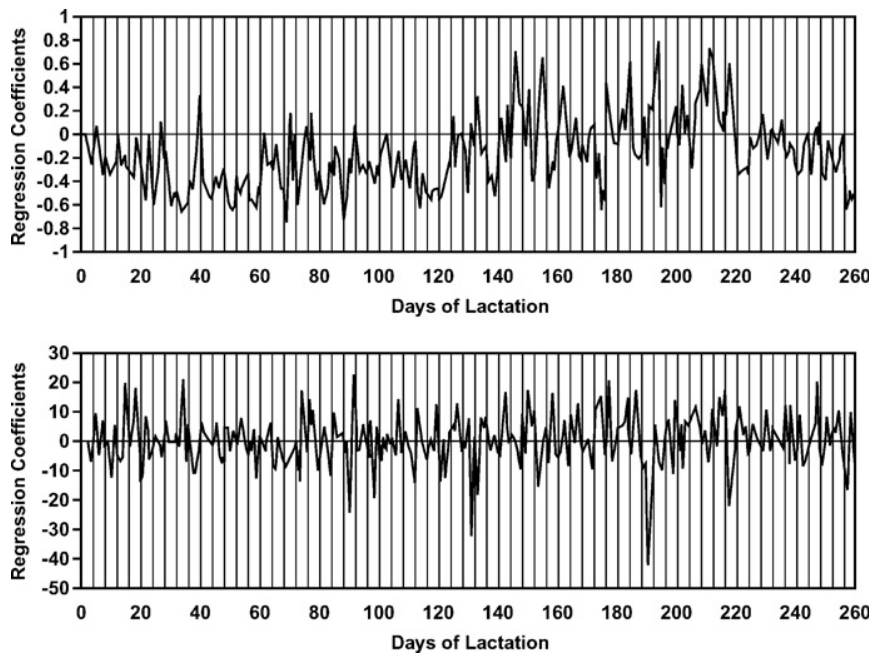

Figure 2. Regression coefficients' values throughout the lactation period. Top panel; current days' body weight divided by 100 (so called $\mathrm{BW}_{0}$ ), bottom panel; the ratio of previous days' body weight to current day body weight $\left(\mathrm{BW}_{-1} / \mathrm{BW}_{0}\right)$. 

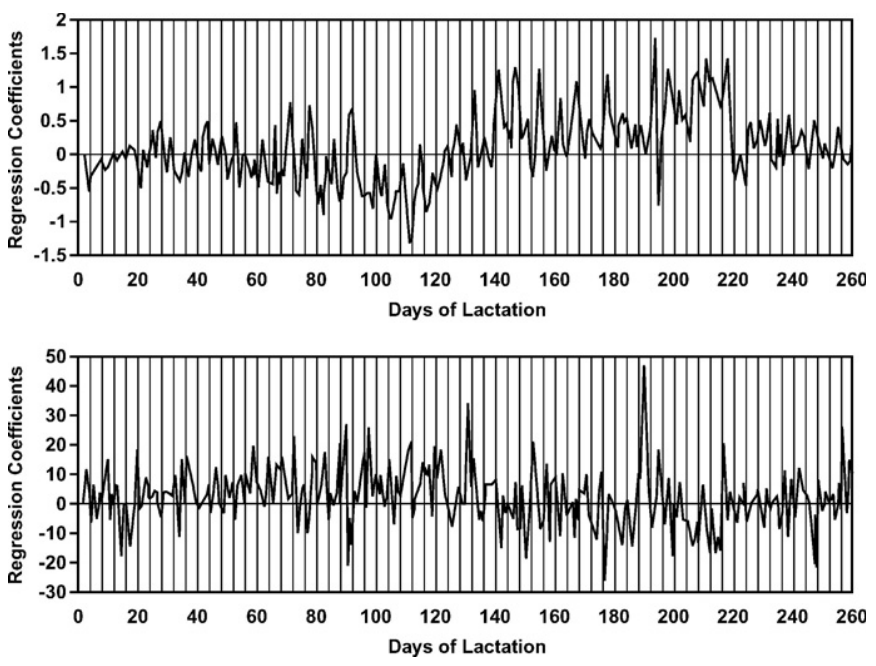

Figure 3. Regression coefficients' values throughout the lactation period. Top panel; milk fat (\%), lower panel is the intercept.

the regression line should be horizontal, and if the appropriate F-statistic is significantly high, we reject the hypothesis $\mathrm{H}_{0}$ and conclude that the model is not valid. So we proceed as follows. Computation of the sum of squared errors (SSE) without and with the
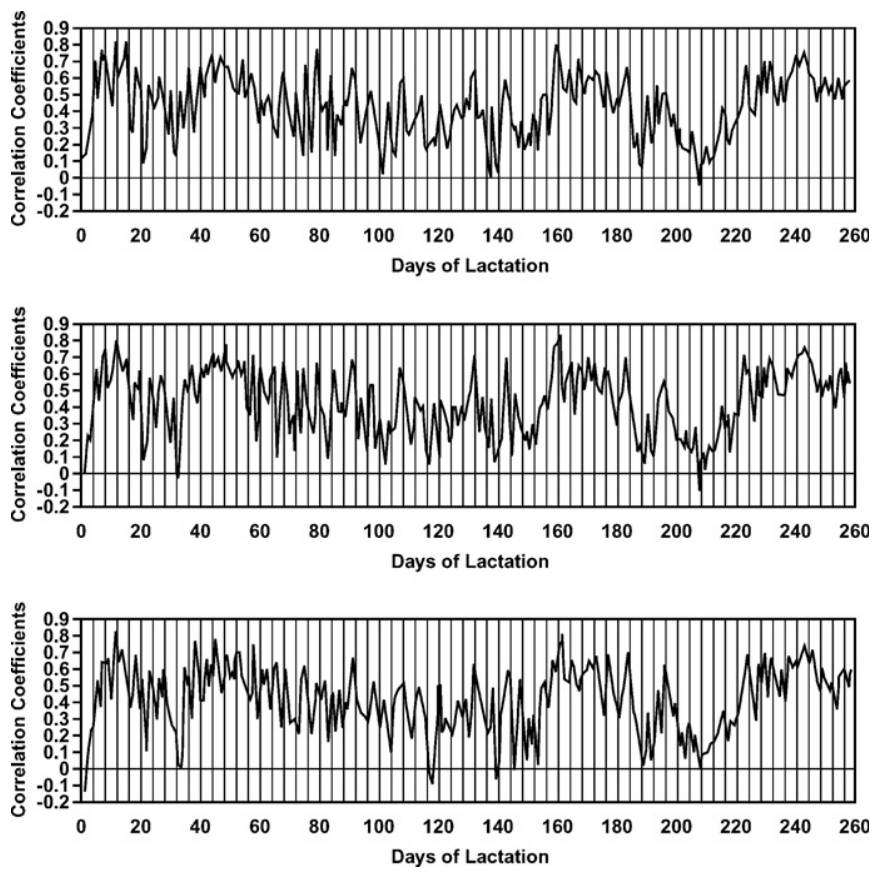

Figure 4. Correlation coefficients throughout the lactation period. Top panel; the ratio of current days' milk yield to current days' body weight multiplied by 100 , middle panel; the ratio of previous days' milk yield to previous days' body weight multiplied by 100 , lower panel; the ratio of $2 \mathrm{~d}$ ago milk yield to $2 \mathrm{~d}$ ago body weight multiplied by 100 .
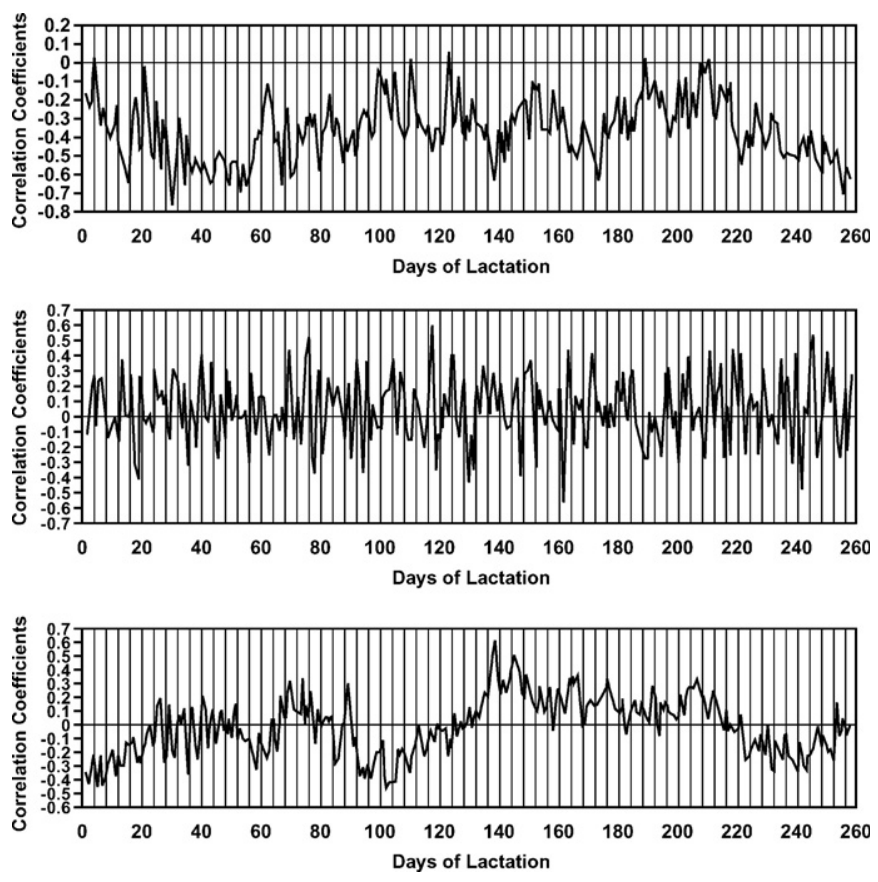

Figure 5. Correlation coefficients throughout the lactation period. Top panel; body weight at the current day divided by 100, middle panel; the ratio of previous days' body weight to current day body weight, lower panel; milk fat.

hypothesis, which corresponds with full and reduced regression model, respectively:

$$
S S E_{f u l l}=\sum_{i=1}^{n}\left(D_{i}-\hat{D}_{i}\right)^{2}
$$

with $\hat{D}_{i}=\mathrm{C}_{0}+\mathrm{C}_{1} \mathrm{Q}_{\mathrm{i}}$, where $\mathrm{C}_{0}$ and $\mathrm{C}_{1}$ are the ordinary least square estimator of $\gamma_{0}$ and $\gamma_{1}$. The reduced regression model implies

$$
\hat{D}_{i}=0 \text { so } S S E_{\text {reduced }}=\sum_{i=1}^{n}\left(D_{i}\right)^{2} .
$$

These 2 SSE yield an $F$-statistic with 2 degrees of freedom (number of regression parameters in composite hypothesis), and n-2 (n observation; 2 estimated regression parameters $\mathrm{C}_{0}$ and $\mathrm{C}_{1}$ ):

$$
F_{2, n-2}=\left(\frac{n-2}{2}\right)\left(\frac{S S E_{\text {reduced }}-S S E_{\text {full }}}{S S E_{\text {full }}}\right)
$$

For mathematical proof we refer to Kleijnen et al. (1998). The assumption of this test is that outputs of the real and model prediction are identically and independently normally distributed; this can be explained by the assumptions behind the multivariable 


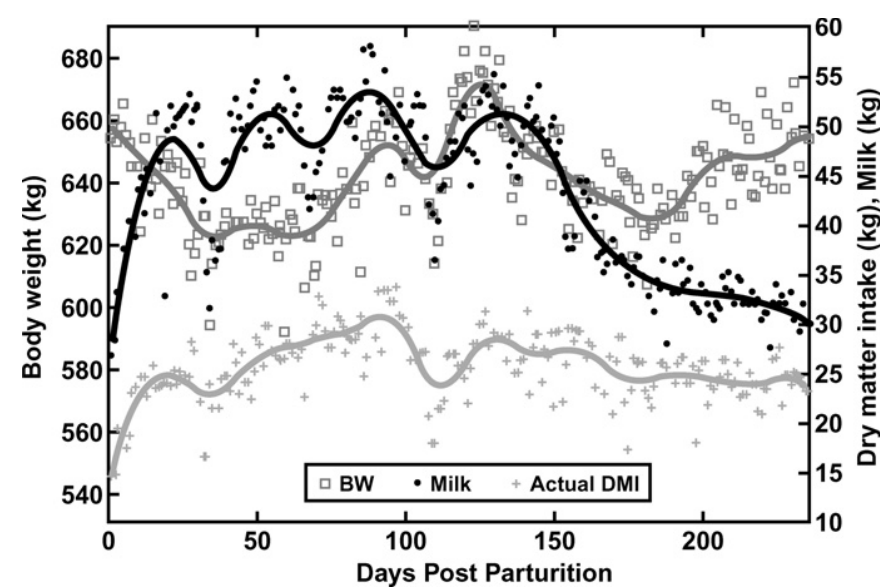

Figure 6. Raw data applied in the model building process: milk yield $(*)$, body weight $(\square)$ and measured dry matter intake (+, socalled DMI) of an individual cow (number 1821). Lines represent the trend lines.

regression and by the central limit theorem. In our case, $\mathrm{F}_{\mathrm{n}} ; 2 ; 0.995 \approx 199(99.5 \%$ significant level, $\mathrm{n}$ days in lactation, the parameters $\mathrm{D}$ and $\mathrm{Q}$ provide 2 degrees of freedom). Matlab's FINV function (Anonymous, 1996) calculated the inverse of the $\mathrm{F}$ cumulative distribution function per each cow. The NRC (2001) equation applied in this study are as follows:

$$
\begin{aligned}
\mathrm{FCM}= & 0.4 * \mathrm{MY}+15^{*} \text { fat } / 100 * \mathrm{MY} \\
\mathrm{DMI}_{\mathrm{NRC}}= & \left(0.372 * \mathrm{FCM}+0.0968 * \mathrm{BW}^{0.75}\right) \\
& *(1-\exp (-0.192 *(\text { wol }+3.67)))
\end{aligned}
$$

where FCM is the $4 \% \mathrm{FCM}$, and wol is weeks of lactation.

(2) Visual analysis. By visual analysis we mean 'eyeballing' the time series of the real system, the forecasting model and of the NRC (2001) to decide whether the models adequately reflect the real system (Kleijnen and van Groenendaal, 1992). The graphs in the figures represent a trend that was computed with the regular Whittaker smoothing algorithm (1923, equations are available in the Appendix below, ex. Figure 6). The models' outputs, with their trend line, are superimposed on the trend of data obtained from the real system (Figure 6).

\section{RESULTS}

\section{Statistical Analysis}

When the forecasting model was applied, the 60 cows (100\%) passed the F-statistical test compared with only $43(71 \%)$ when the NRC (2001) model was applied
(Table 3 ). The F-statistic tests (99.5\% confidence level,) suggest that, under the circumstances of this trial, the Forecasting model was more valid than the NRC model. This conclusion was supported by the visual analysis (Figures 7 to 8, 10 to 14, see below).

\section{Visual Analysis}

Data on 8 cows are presented in Figures 6 to 14. By nature, the cows differ in terms of BW, MY, and DMI curves, and the model should be able to handle a variety of cases. It can be seen (Figure 6) that cow 1821 reached a yield of $50 \mathrm{~kg}$ of milk per day within $1 \mathrm{mo}$, showed a rapid fall during the fifth month, up to 150 $\mathrm{d}$ in lactation, and than gained BW and exhibited increasing appetite. In general, from Figure 7, it can be seen that the Forecasting model DMI followed the measured DMI rather well, even during the abnormal fifth month, and that the NRC model (Figure 8) was more accurate during $\mathrm{d} 40$ to 50 and during the first 10 d. Data for cow 1833 are presented in Figures 9 to 11. This cow showed an a typical BW gain pattern from $d 40$ to 80 , and the Forecasting model follows the intake curve but with a phase delay; the NRC model is less accurate (Figure 11) in these days.

Cow 1735 (Figure 12) reached a yield of $40 \mathrm{~kg}$ of milk per day within 1 mo, showed a rapid fall during the fifth month, up to $150 \mathrm{~d}$ in lactation, and then gained BW and exhibited increasing appetite. In general, from Figure 12 it can be seen that the Forecasting model DMI followed the measured DMI rather well, even during the abnormal fifth month, and that the NRC model (Figure 12) is more accurate during the first 10 d. Data for cow 1831 are given in Figure 12; although the MY and BW follow typical patterns, it can be seen that the NRC model failed to predict the DMI after d 150, whereas the Forecasting model prediction was more accurate after d 150. Even though cow 1828 became ill around d 140 (Figure 13), had dropped MY, lost weight, and had low DMI, the Forecasting model followed her individual measured DMI curve. The Forecasting model also matched the DMI curve peaks at the early stage of lactation better than the NRC model did (Figure 13). Even though the daily MY of cow 1662 had dropped severely from $42 \mathrm{~kg}$ at d 100 to $12 \mathrm{~kg}$ at d 175 (Figure 13), it can be seen that the Forecasting model accuracy was higher than that of the NRC model (Figure 13). The milk yield of cow 1511 (Figure 14) had increased to around $50 \mathrm{~kg} / \mathrm{d}$ on d 120, after which it decreased monotonically; it can be seen (Figure 14) the Forecasting model followed the reality in the early stage of lactation as well as in the final phase. Cow 1712 (Figure 14) had achieved a daily yield of $50 \mathrm{~kg}$ of milk by d 30, and maintained a high 
HALACHMI ET AL.

Table 3. Statistical tests at the validation phase; comparing the Forecasting model with the NRC model. Both models predict DMI of each individual cow kept in the herd.

\begin{tabular}{|c|c|c|c|c|}
\hline \multirow[b]{2}{*}{ Cow $^{1}$} & \multicolumn{2}{|c|}{ Forecasting DMI model } & \multicolumn{2}{|c|}{ NRC DMI model } \\
\hline & $F$-test & $\mathrm{MAE}^{2}$ & $F$-test & MAE \\
\hline \multicolumn{5}{|l|}{ Group 1 (year 1996) } \\
\hline (1) 1622 & 57 & 2.34 & 12 & 1.21 \\
\hline (2) 1667 & 141 & 3.66 & 41 & 1.39 \\
\hline (3) 1775 & 15 & 1.51 & 21 & 1.2 \\
\hline (4) 1749 & 5 & 1.64 & 35 & 1.9 \\
\hline (5) 1707 & 1 & 2.36 & 19 & 1.06 \\
\hline (6) 1759 & 54 & 2.73 & 13 & 1.27 \\
\hline (7) 1580 & 1 & 2.34 & 25 & 2.97 \\
\hline (8) 1760 & 36 & 3.26 & 48 & 1.68 \\
\hline (9) 1814 & 8 & 1.52 & 238 & 3.35 \\
\hline (10) 1833 & 15 & 1.03 & 18 & 1.18 \\
\hline (11) 1644 & 2 & 1.97 & 40 & 1.92 \\
\hline (12) 1718 & 35 & 3.9 & 95 & 2.12 \\
\hline (13) 1761 & 166 & 7.42 & 24 & 2.21 \\
\hline (14) 1846 & 18 & 1.55 & 255 & 4.17 \\
\hline (15) 1733 & 6 & 2.51 & 16 & 2.19 \\
\hline (16) 1821 & 2 & 1.45 & 112 & 2.39 \\
\hline (17) 1608 & 35 & 2.35 & 13 & 1.08 \\
\hline (18) 1665 & 136 & 5.18 & 36 & 1.7 \\
\hline (19) 1773 & 90 & 6.24 & 154 & 2.21 \\
\hline (20) 1825 & 20 & 2.76 & 99 & 4.44 \\
\hline$(21)-(39)^{*}$ & & & & \\
\hline $\begin{array}{l}\text { Number of cows pass the statistical } \\
\text { test }(F<199) \text { : }\end{array}$ & $39(100 \%)$ & & $31(79$ & \\
\hline Average: & 46.7 & 2.35 & 106.2 & 2.68 \\
\hline \multicolumn{5}{|l|}{ Group 2 (year 2002) } \\
\hline (1) 1906 & 37 & 4.24 & 174 & 4.51 \\
\hline (2) 2003 & 110 & 3.35 & 350 & 4.58 \\
\hline (3) 2124 & 23 & 2.37 & 136 & 2.13 \\
\hline (4) 2148 & 5 & 3.77 & 38 & 3.21 \\
\hline (5) 1942 & 77 & 4.2 & 100 & 2.38 \\
\hline (6) 2048 & 46 & 4.3 & 191 & 4.57 \\
\hline (7) 2136 & 32 & 1.42 & 5 & 1.74 \\
\hline (8) 2153 & 125 & 4.02 & 243 & 5.58 \\
\hline (9) 1852 & 8 & 6.57 & 141 & 3.71 \\
\hline (10) 1955 & 96 & 3.3 & 19 & 2.35 \\
\hline (11) 2063 & 29 & 4.38 & 10 & 1.3 \\
\hline (12) 2141 & 95 & 3.17 & 246 & 3.83 \\
\hline (13) 2160 & 71 & 4.11 & 3 & 1.65 \\
\hline (14) 1871 & 23 & 2.96 & 71 & 2.4 \\
\hline (15) 1962 & 3 & 1.55 & 77 & 1.95 \\
\hline (16) 2072 & 1 & 1.97 & 34 & 2.65 \\
\hline (17) 2145 & 7 & 4.23 & 189 & 3.42 \\
\hline (18) 1892 & 26 & 2.79 & 2 & 1.95 \\
\hline (19) 2002 & 14 & 10.5 & 89 & 9.61 \\
\hline (20) 2118 & 21 & 3.76 & 76 & 2.75 \\
\hline (21) 2147 & 50 & 2.95 & 229 & 3.78 \\
\hline $\begin{array}{l}\text { Number of cows pass the statistical } \\
\text { test }(F<199)\end{array}$ & $21(100 \%)$ & & $17(81$ & \\
\hline Average: & 40.0 & 3.80 & 115.3 & 3.33 \\
\hline
\end{tabular}

${ }^{1}$ Cows used for model development.

${ }^{2}$ Mean absolute error (MAE) is the daily model outputs minus measured dry matter intake of the individual cow. The number is the average along the entire lactation period.

yield until d 155. In general along the lactation period of cow $1712 \mathrm{~s}$, the Forecasting model followed the measured DMI better than that of the NRC model (Figure 14), even though the BW of cow 1712 did not decline at the beginning of lactation, as expected in the highyielding dairy cow.

\section{DISCUSSION}

The NRC (2001) and the Forecasting models share the same concept: to use only animal-related factors to calculate the DMI. In fact, these are basically the same factors: MY, BW, milk fat, and time after calving. 


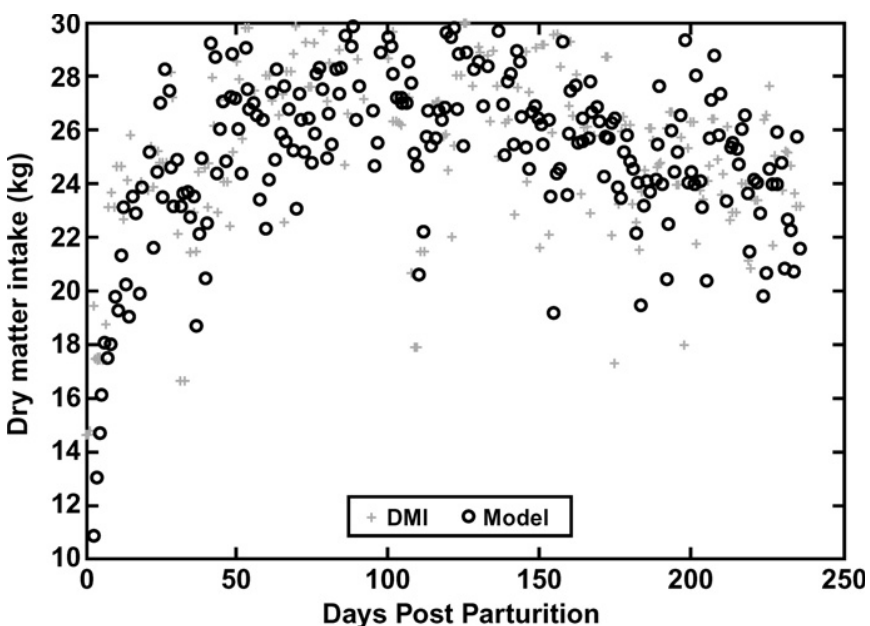

Figure 7. Model prediction $(\bigcirc)$ vs. measured DMI (+) of the individual cow, number 1821 .

However, the 2 models differ fundamentally in 2 aspects: a) the way these factors are used, and b) the modeling approach. From many visual analyses of daily food intake that were related to daily BW changes (see Maltz and Metz, 1994; Maltz et al., 1997), we could identify BW changes responding to DMI changes. It can be explained; every kilogram of DM in the digestive tract is accompanied by as much as $8 \mathrm{~kg}$ of water. Hence, the DMI changes are reflected directly in BW (Maltz and Metz, 1994; Maltz et al., 1997). That is why we preferred using absolute BW and not metabolic BW (like the NRC). It is the gastrointestinal content and not metabolic BW that responds most to the daily differences in DMI. This is also the reason

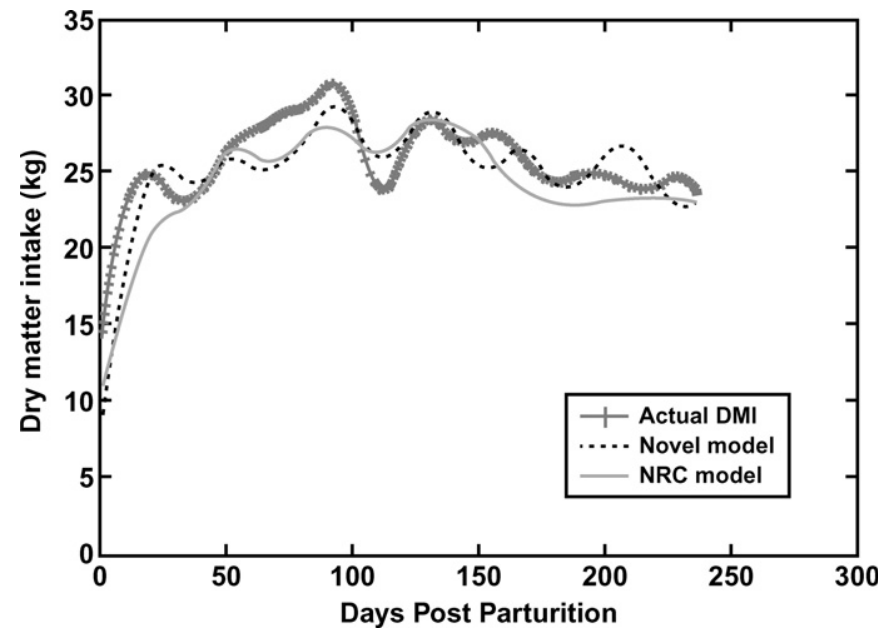

Figure 8. Comparing model prediction (- - ) vs. NRC model (-) over the measured DMI (+) of the individual cow, number 1821.

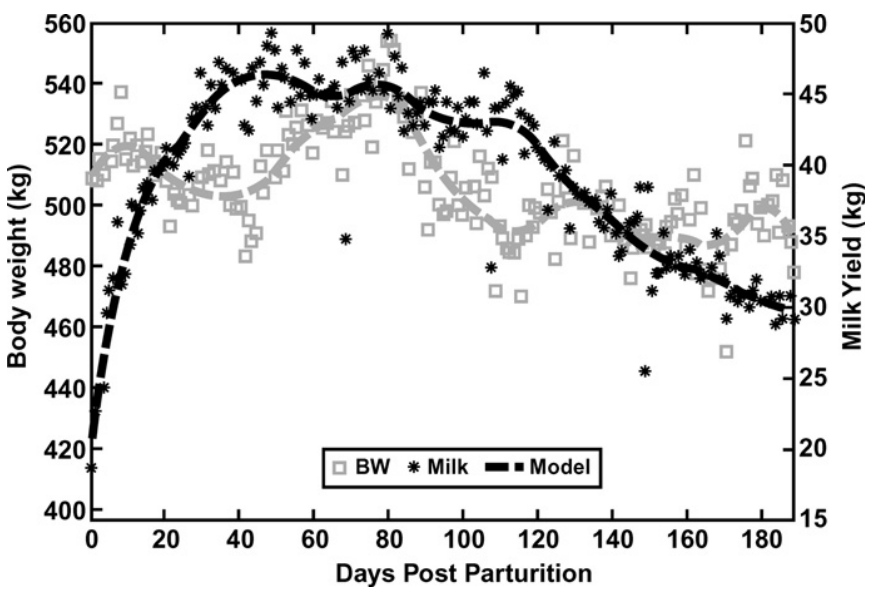

Figure 9. Data used in the model: milk yield $(*)$ and body weight $(\square)$ of an individual cow (number 1833). Broken lines represent the trend lines.

that the BW ratio of 2 successive days was included in the model and later was also justified by the stepwise procedure. The NRC (2001) incorporates a periodically measured factor (milk fat) in terms of $4 \%$ FCM. Therefore, it imposes a constant periodically measure factor (usually once a month) on a daily measured one (MY). This might impose step-function shifts whenever a new fat recording is performed, which is especially significant in early and late lactation when milk fat changes are sometimes rather rapid and large. This, in our opinion, might weaken the model, while our model presents these 2 factors separately, thus frees the continuously measure factor (MY) from the shortcomings of the periodically measured one (milk fat). However, when milk composition will be available

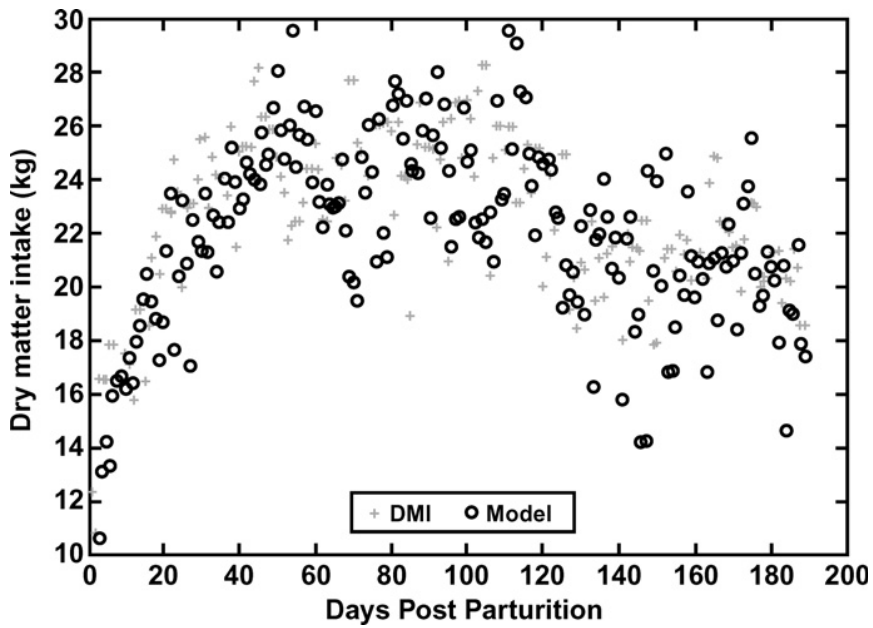

Figure 10. Model prediction $(\bigcirc)$ vs. measured DMI (+) of the individual cow, number 1833. 


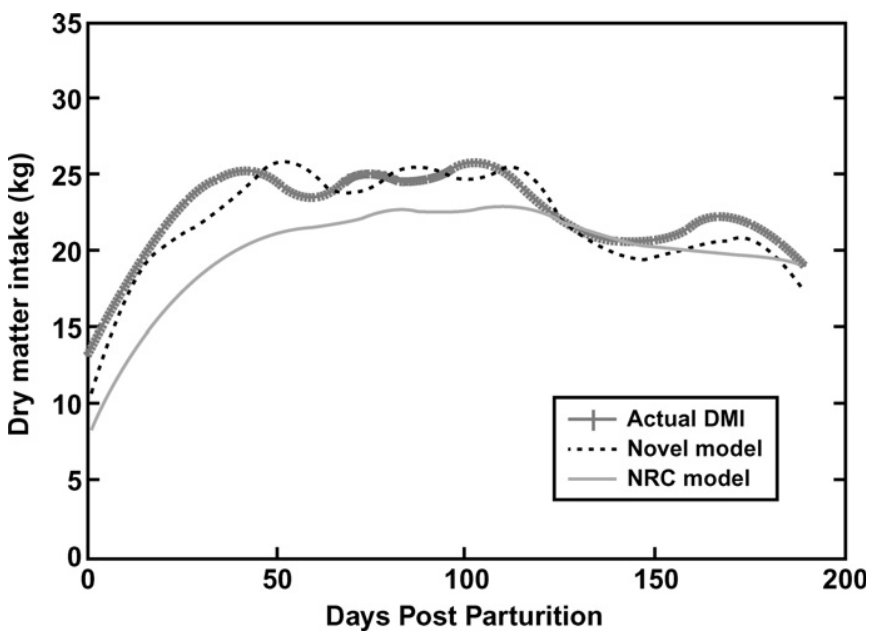

Figure 11. Comparing model prediction $(---)$ vs. NRC model (-) over the measured DMI (+) of the individual cow, number 1833.

daily like MY (Schmilovitch et al., 2000), this handicap of using FCM will be lifted. In addition, we used MY as related to $\mathrm{BW}$ rather then MY as absolute value (or absolute FCM). We incorporated an efficiency element into the model. This approach was justified by the stepwise regression procedure. Indeed, the significance of MY related to BW and referred to as "cow potential" as a management tool was described in several papers (Maltz et al., 1991; Spahr et al., 1993). Last but not least, information history reflects on current performance. The fact that any day's performance reflects also "historical" events is partly the result of our "artificial" deviation of the "day," say from one daily feeding to the next. Unlike MY that is not affected by this factor because it is executed daily at the same hours, eating, although strongly effected by diurnal routine, is not restricted to the same hours. Therefore, if a cow eats $5 \mathrm{~kg}$ one day just before feeding time and the next day combines this meal to after feeding time it will be reflected in the from feeding to feeding diurnal fluctuations. Another possibility is purely physiological, especially during transition time. It is not uncommon that a cow will be off her food one day and compensate for it in the next. The milk production driving force sometimes puts the cow in a "struggling" situation, that is reflected by disability to increase DMI that are accompanied by parallel fluctuations in MY (Maltz and Metz, 1994; Maltz et al., 1997). These daily fluctuations in DMI and in the other animal-related factors and their mutual response to each other, suggested that a daily-based model is preferable in order not to lose this information that might be screened when using several day averages.
We adopted a modeling technique that in our opinion represents the ever-changing physiological status of the animal along the lactation period differently than that of the NRC. In the predictive model, the relative weight of each of the animal-related factors changes along lactation by using different regression coefficients per a day. In the NRC (2001), the whole lactation periods are linked by the formula. This linkage, in our opinion, is less restricting when the different stages of lactation are resigned different coefficients of each day.

This model was found to be statistically valid with 99.5 confidence level. Its performance was compared statistically and visually to that of the NRC model, and it was not inferior. Data from 17,087 lactation weeks were used for evaluation and development of the NRC (2001) equations. Likewise, data from 15,000 lactation days was used in the Forecasting model. In further research, more data are needed to evaluate the new model before it can be operated in commercial farms on a daily basis, incorporated in the self-feeder or robot software, perhaps also to support decision making concerning culling, i.e., keeping only the most cost-effective cows, which are not always the highestyielding cows.

The data in this study were collected from cows that were under different nutritional and hormonal treatments. In spite of the differences in diet efficiency as influenced by treatments as was reported (Moallem et al., 2000) the model's validity stood up to the statistical criteria.

In general, the modeler's task is to produce a simplified yet valid abstraction of the real system of interest. The "perfect model' would be the real system itself; by definition, any model is a simplification of reality. In practice, however, the model should be 'satisfying,' in accordance with the goals set for it. During model development phases, different parameters were considered, most of them rejected because of lack of contribution, including body condition. In the future, body condition would have potential contribution if it can be (1) measured objectively and (2) automatically. Unfortunately, currently it is a visual subjective estimation and that could be the reason for its poor contribution to the model. Not all the animal-related behavioral factors were examined. For example, activity or laying behavior may improve the model's performance. Activity sensors are currently used as estrus detectors, and their contribution to DMI modeling should be evaluated, because an animal that roams is eating less, and an animal that spends a lot of time lying down spends less time eating. Lying down behavior monitoring (Champion et al., 1997) is not yet a commercially available, but it may well be in the near future and should 
cow \#1735
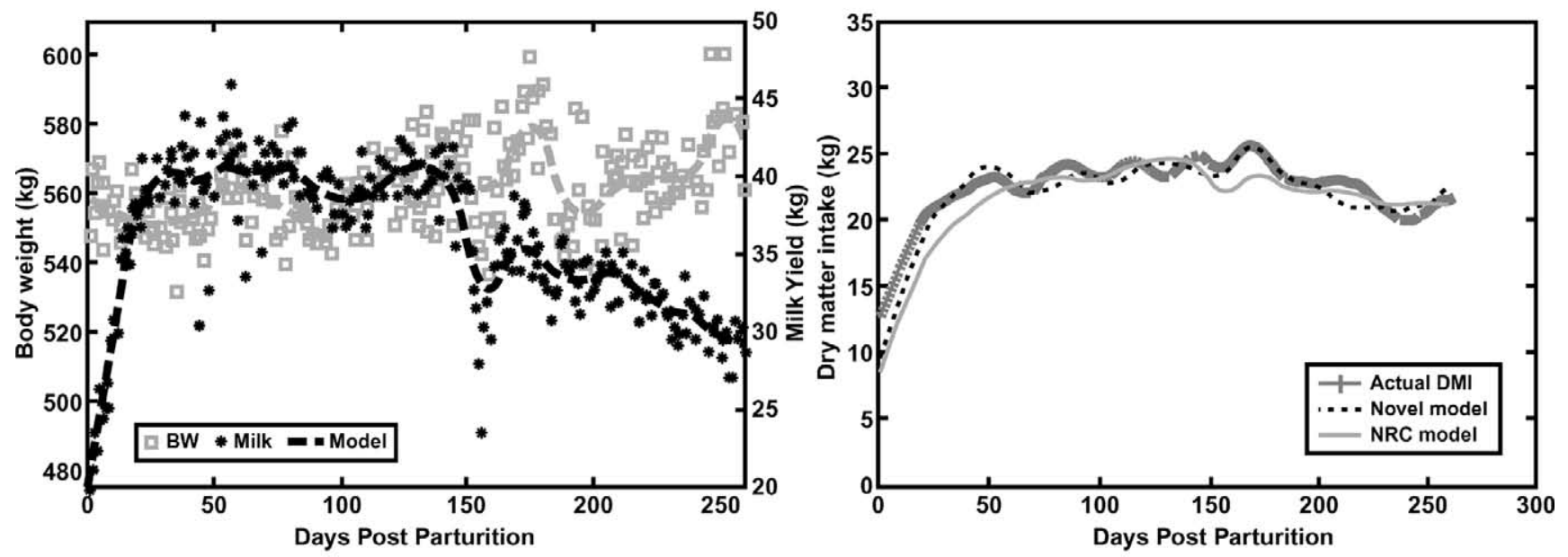

cow \#1775
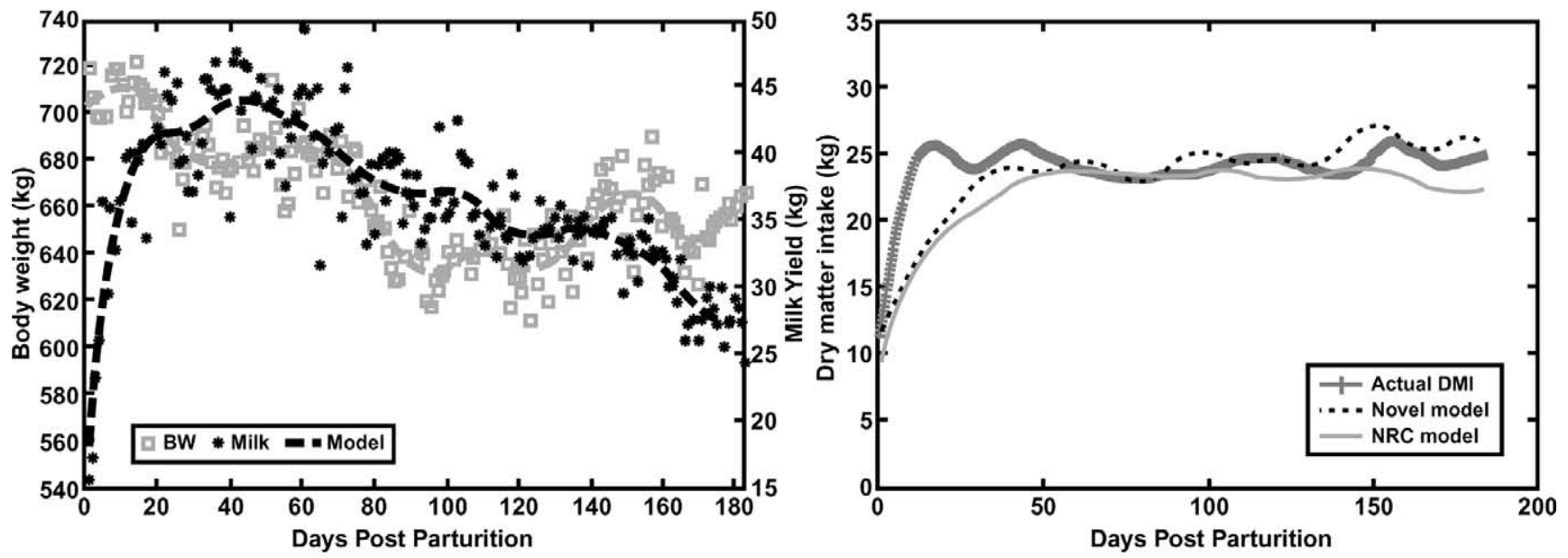

cow \#1831
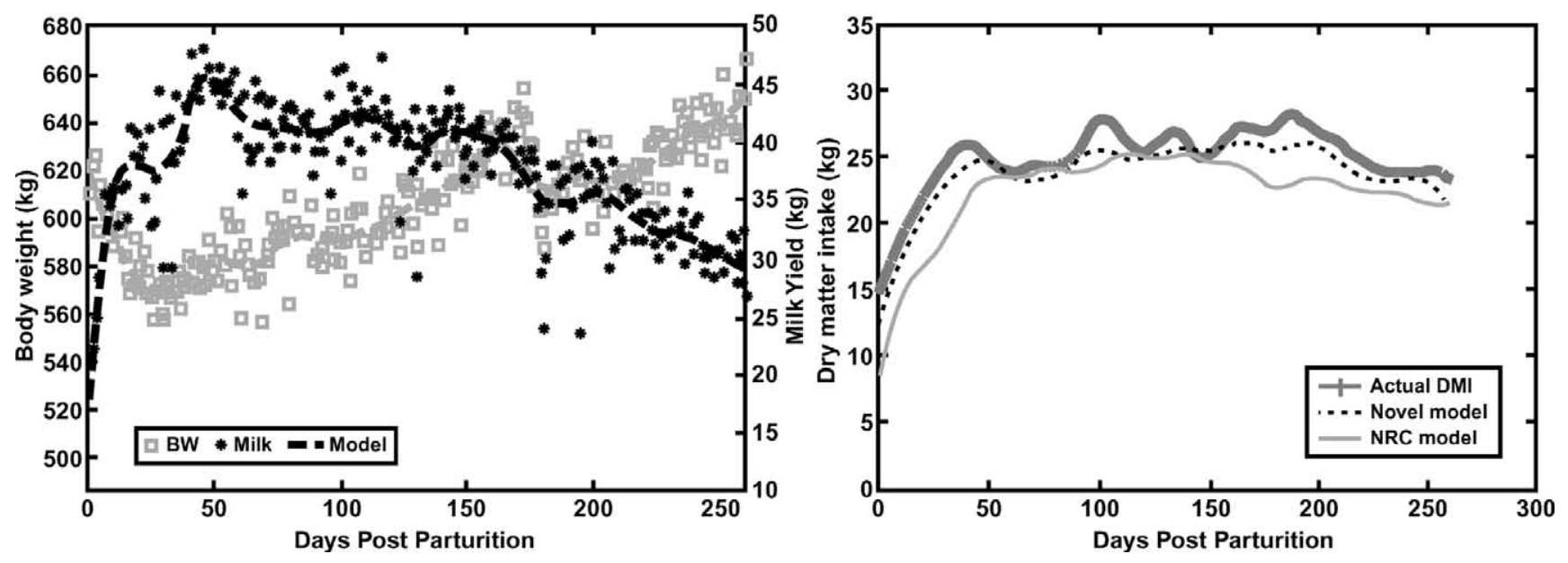

Figure 12. Daily yield $(*)$ and body weights $(\square)$ (left-side figures), and comparison between model prediction (--) vs. NRC model (-) over the measured DMI trend lines (right-side figures) (+) of 3 cows. Broken lines in left-side figures represent trends. 
cow \#1626
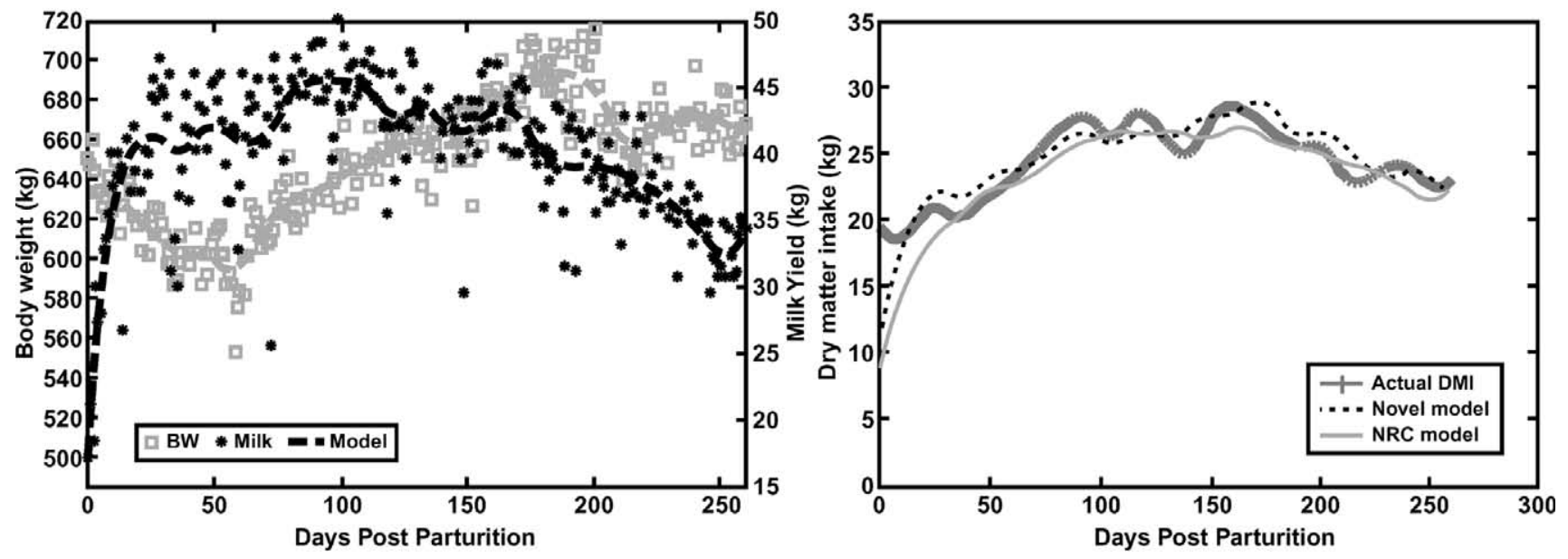

cow \#1828
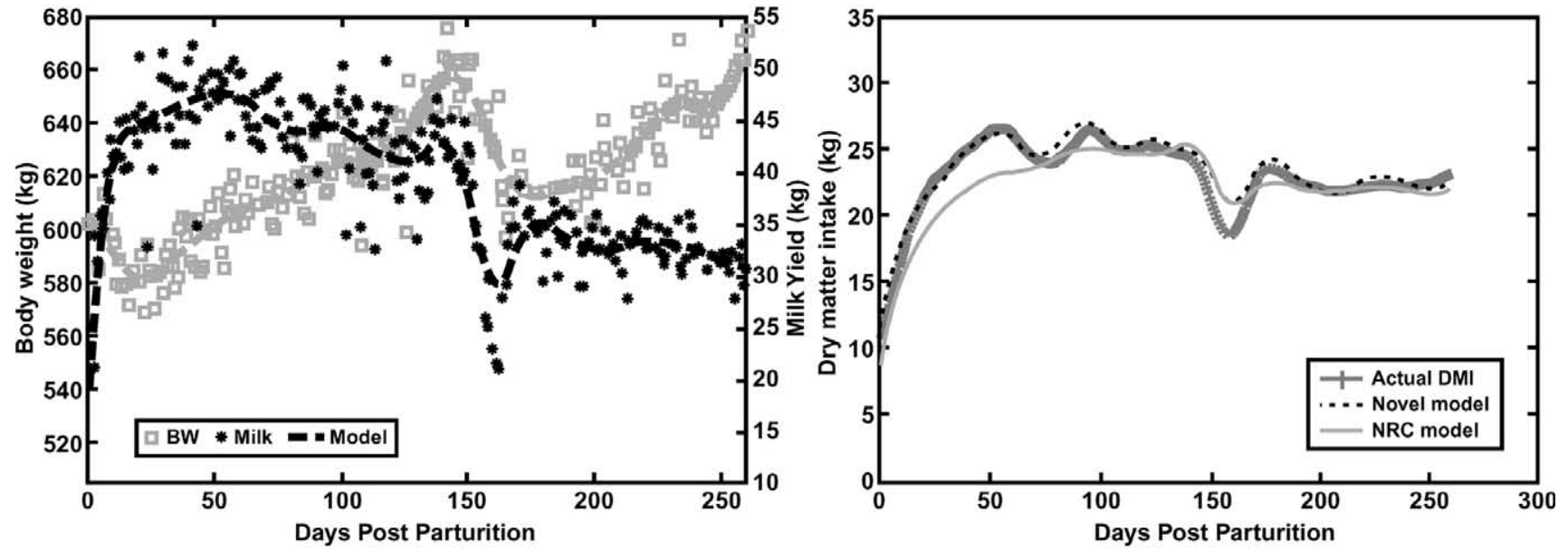

cow \#1662
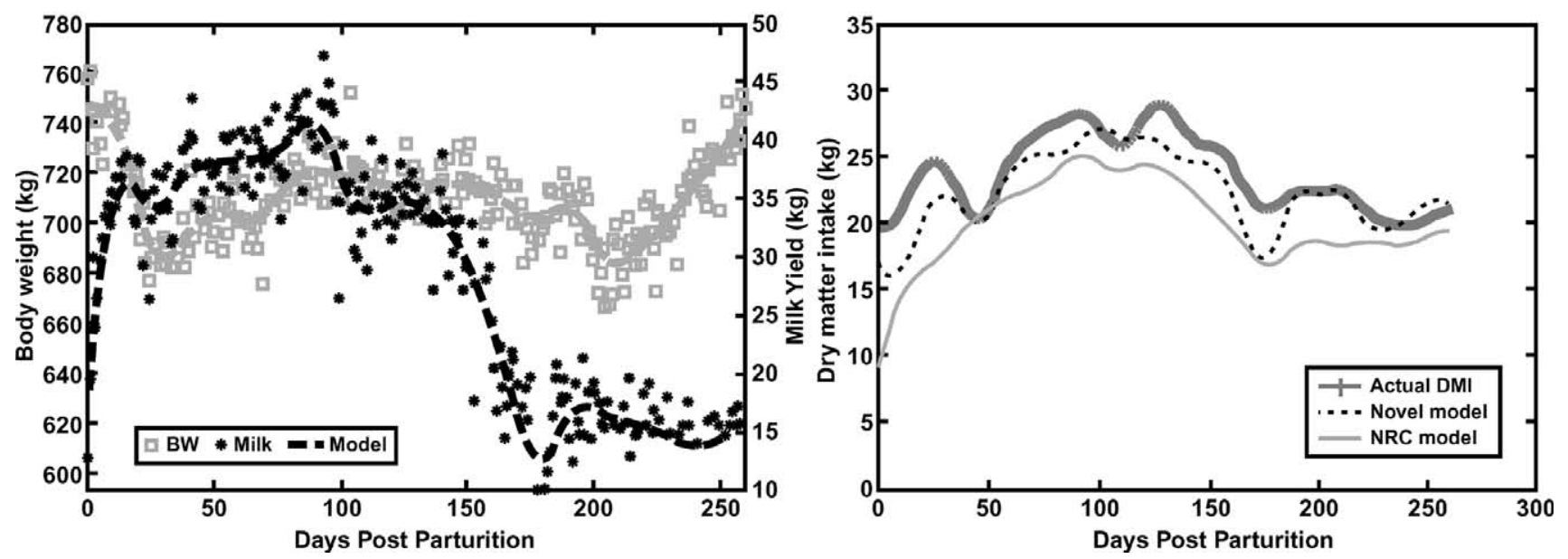

Figure 13. Daily yield $\left(^{*}\right)$ and body weights $(\square)$ (left-side figures), and comparison between model prediction (--) vs. NRC model (-) over the measured DMI trend lines (right-side figures) (+) of 3 cows. Broken lines in left-side figures represent trends. 
cow \#1511
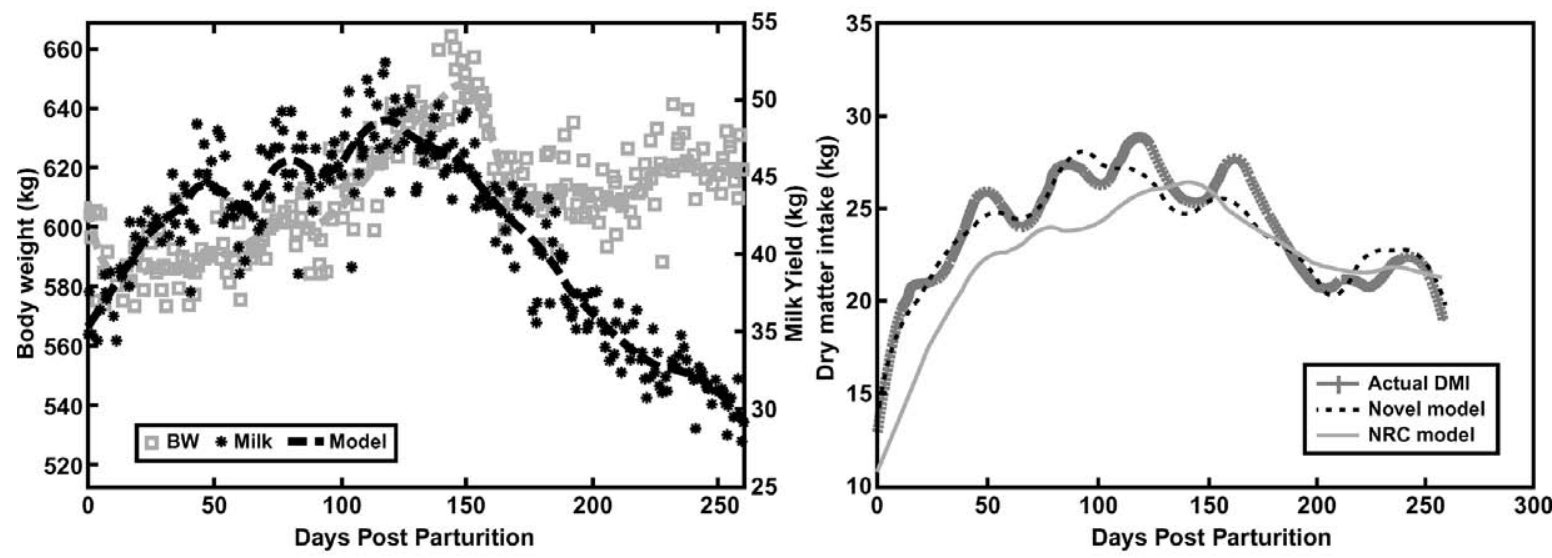

cow \#1712
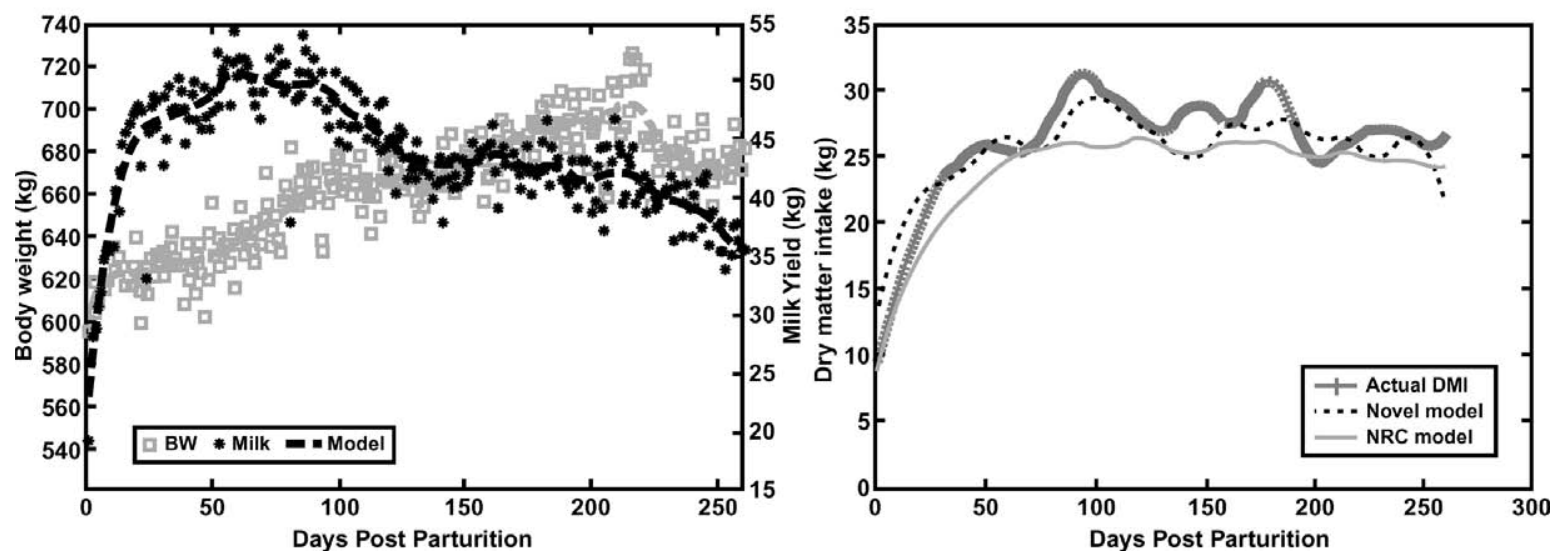

Figure 14. Daily milk yield (*) and body weights $(\square)$ (left-side figures) and comparison between model prediction (-- - ) vs. NRC model (-) over the measured DMI trend lines (right-side figures) (+) of 2 cows. Broken lines in left-side figures represent trends.

be also evaluated as a contributor to DMI modeling. Environmental factors such as ambient temperature and humidity are also likely to have an impact over DMI. These factors should be incorporated only if they are measured continuously in the vicinity of the cow. In the absence of such ability, we did not incorporate these factors into the model.

\section{CONCLUSION}

In general, no model can be proven statistically to be a precise representation of the underlying real system. Nevertheless, in our particular case, we found no statistical evidence against the validity of our model (99.5\% confidence level). Both statistical and visual comparison of its performance to that of the NRC model suggests that this model can be useful for research and practical application.
After validation with a larger number of cows, this model may be used as a complementary model to the NRC when individual feeding is needed for high-yield cows. The Forecasting model might facilitate the improvement of individual feeding management that is based on a concentrate self-feeder, used either stand alone or in a milking robot.

\section{ACKNOWLEDGMENTS}

The authors thank reviewers of JDS for their help and critical comments that reshaped the manuscript into its final version.

\section{REFERENCES}

Anonymous. 1996. MATLAB User's Guide Version 5, MathWorks Inc, Natick, MA. 
Champion, R. A., S. M. Rutter, and P. D. Penning. 1997. An automatic system to monitor lying, standing and walking behaviour of grazing animals. Appl. Anim. Behav. Sci. 54:291-305.

Devir, S., J. A. Renkema, R. B. M. Huirne, and A. H. Ipema. 1993. A new dairy control and management system in the automatic milking farm: Basic concepts and components. J. Dairy Sci. 76:3607-3616.

Devir, S., E. Maltz, and J. H. M. Metz. 1997. Strategic management planning and implementation at the milking robot dairy farm. J. Comput. Electron. Agric.-SI. 17:95-110.

Eilers, P. H. C., and B. Marx. 1996. Flexible smoothing with splines and penalties. Stat. Sci. 11:89-121.

Halachmi, I. 2000. Designing the optimal robotic barn. Part 2: Behaviour-based simulation. J. Agric. Eng. Res. 77:67-79.

Halachmi, I. 2004. Designing the automatic milking farm in a hot climate. J. Dairy Sci. 87:764-775.

Halachmi, I., E. Maltz, J. H. M. Metz, and S. Devir. 1997. The body weight of the dairy cow: II. Modeling individual voluntary food intake based on body weight and milk production. Livest. Prod. Sci. 48:244-246.

Halachmi, I., Y. Edan, E. Maltz, U. M. Peiper, I. Brukental, and U. Moalem. 1998a. A real-time control system for individual dairy cow food intake. Comp. Electron. Agric. 20:131-144.

Halachmi, I., J. A. P. Heesterbeek, and J. H. M. Metz. 1998b. Designing the optimal robotic milking barn, using simulation. Pages 13-16 in Proc. Dutch-Japanese Workshop on Precision Dairy Farming, Wageningen, The Netherlands.

Halachmi, I., A. Dzidic, J. H. M. Metz, L. Speelman, A. A. Dijkhuizen, and J. P. C. Kleijnen. 2001. Validation of simulation model for robotic milking barn design: Case study. Eur. J. Ops. Res. 134:165-176.

Halachmi, I., and J. H. M. Metz, A. van't Land, S. Halachmi, and J. P. C. Kleijnen. 2002. Optimal facility allocation in a robotic milking barn. Trans. ASAE 45:1539-1546.

Hogeveen, H., W. Ouweltjes, C. J. A. M. de Koning, and K. Stelwagen. 2002. Milking interval, milk production and milk flow-rate in an automatic milking system. Livest. Prod. Sci. 72:157-167.

Ketelaar-De Lauwere, C. C., A. H. Ipema, J. H. M. Metz, J. P. T. M. Noordhuizen, and W. G. P. Schouten. 1999. The influence of the accessibility of concentrate on the behaviour of cows milked in an automatic milking system. Netherlands J. Agric. Sci. 47:1-16.

Kleijnen, J. P. C., and W. J. H. van Groenendaal. 1992. Simulation: A Statistical Perspective. John Wiley, Chichester, England.

Kleijnen, J. P. C. 1987. Statistical Tools for Simulation Practitioners. Marcel Dekker, Inc., New York, NY.

Kleijnen, J. P. C., B. Bettonvil, and W. J. H. van Groenendaal. 1998. Validation of trace-driven simulation models: A novel regression test statistical perspective. Manage. Sci. 44:812-819.

Maltz, E., O. Kroll, R. Sagi, S. Devir, S. L. Spahr, and A. Genizi. 1991. Milk yield parity and cow potential as variables for computerized concentrates supplementation strategy. J. Dairy Sci. 74:22772289 .

Maltz, E., and J. H. M. Metz. 1994. An individual approach to manage the dairy cow: A challenge for research and practice. Pages 267-282 in Int. Symp. Prospects for Future Dairying: A Challenge for Science and Industry. Alfa Laval Agri, Tumba, Sweden and Swedish University of Agricultural Sciences, Uppsala, Sweden.

Maltz, E., S. Devir, J. H. M. Metz, and H. Hogeveen. 1997. The body weight of the dairy cow: I. Introductory study into body weight changes in dairy cows as a management aid. Livestock Prod. Sci. 48:175-186.

Maltz, E., N. Livshin, S. Devir, and D. Rosenfeld. 2002. Using online data in management of milking frequency and concentrates supplementation in the AMS Herd. Pages 33-44 in The First North American Conference on Robotic Milking, Toronto, Ontario, Canada.

Mertens, D. R. 1987. Predicting intake and digestibility using mathematical models of ruminal function. J. Anim. Sci. 64:1548-1558.

Moallem, U., Y. Folman, and D. Sklan. 2000. Effects of somatotropin and dietary calcium soaps of fatty acids in early lactation on milk production, dry matter intake, and energy balance of highyielding dairy cows. J. Dairy Sci. 83:2085-2094.

National Research Council. 2001. Nutrient Requirements of Dairy Cattle. 7th rev. ed. National Academy Press, Washington, DC.

Roseler, D. K., D. G. Fox, L. E. Chase, A. N. Pell, and W. C. Stone. 1997a. Development and evaluation of equations for prediction of feed intake for lactating Holstein cows. J. Dairy Sci. 80:878-893.

Roseler, D. K., D. G. Fox, A. N. Pell, and L. E. Chase. 1997b. Evaluation of alternative equations for prediction of intake for Holstein dairy cows. J. Dairy Sci. 80:864-877.

Schmilovitch, Z., E. Maltz, A. Hoffman, H. Egozi, Y. Belnky, I. Shmulevich, and A. Notea. 2000. Low cost NIR sensor for on-line milk composition measurement. Paper R6207 in The XIV Conference Memorial CIGR World Congress Tsukuba, Japan.

Spahr, S. L., R. D. Shanks, G. C. McCoy, E. Maltz, and O. Kroll. 1993. Lactation potential as a criterion for total mixed ration feeding strategy for dairy cows. J. Dairy Sci. 76:2723-2735.

Spahr, S. L., and E. Maltz. 1997. Herd management for robot milking. J. Comput. Electronics Agric. -SI. 17:53-62.

Whittaker, E. T. 1923. On a new method of graduation. Proc. Edinburgh Math. Soc. 41:63-75.

\section{APPENDIX}

Trend-line. Daily milk yield, BW, and DMI of the individual cow are noisy and variable (Maltz and Metz, 1994; Halachmi et al., 1997; Maltz et al., 1997), so that it is difficult to investigate a trend. To present the model results in the paper, a smoothing algorithm (Whittaker, 1923) was implemented in Matlab (Eilers and Marx, 1996; Anonymous, 1996). Let y be a term in the given time series with m elements, and $\mathrm{z}$ be the corresponding point on the trend curve that we are trying to determine. The least squares (so called ' $S$ ') of differences determine how well one data series conforms to another: $S=\sum_{i=1}^{m} w_{i}\left(y_{i}-z_{i}\right)^{2}$, in which w is a vector of weights with $w_{\mathrm{i}}=0$, where observations are missing and $w_{\mathrm{i}}=1$ otherwise. We measured how rough a series is by looking at the differences between adjacent values. A roughness (so-called ' $R$ ') measure was

$$
R=\sum_{i}\left(z_{i}-z_{i-1}\right)^{2}=\sum_{i}\left(\Delta z_{i}\right)^{2}
$$

D is the differencing matrix such that $\boldsymbol{D} \boldsymbol{z}=\boldsymbol{\Delta z}$, looks like:

$$
D=\left[\begin{array}{ccccc}
-1 & 1 & 0 & 0 & 0 \\
0 & -1 & 1 & 0 & 0 \\
0 & 0 & -1 & 1 & 0 \\
0 & 0 & 0 & -1 & 1
\end{array}\right]
$$

when $\mathrm{m}=5$ and in general it has $\mathrm{m}-1$ rows and $m$ columns.

The solution of the minimization problem is found from the following system of linear equations: $(I+$ 
$\left.\lambda D^{\prime} D\right) z=y$, where $I$ is the identify matrix. The number of equations is equal to the length of the data series, $\mathrm{m}$. We have to minimize $P=\mathrm{S}+\lambda \mathrm{R}=(y-z)^{\prime} W(y-z)$ $+\lambda|D z|^{2}$, i.e., to find a value of $z$ such that a weighted sum of $S$ and $R$ is minimized. So we minimized the penalized least squares estimation $\mathbf{P}=\mathbf{S}+\lambda \mathbf{R}$ in which $\lambda \mathrm{R}$ is called a penalty. A high value of $\lambda$ means we judge smoothness more important than a good fit to the data. The solution was found from $\left(\boldsymbol{W}+\lambda \boldsymbol{D}^{\prime} \boldsymbol{D}\right) \boldsymbol{z}=$ $\boldsymbol{W} \boldsymbol{y}$, in which $\boldsymbol{W}$ is a diagonal matrix with weights $\mathrm{w}$ on the diagonal with $\mathrm{w}_{\mathrm{i}}=0$, where observations are missing and $\mathrm{w}_{\mathrm{i}}=1$ otherwise. Matlab has a function to compute this calculations, the Matlab implementation has only 5 lines of code:

$$
\text { function } \begin{aligned}
{[\mathrm{z}] } & =\operatorname{trend}(\operatorname{lambda}, \mathrm{y}) \\
\mathrm{w} & =\operatorname{ones}(\operatorname{size}(\mathrm{y})) ;
\end{aligned}
$$

$$
\begin{aligned}
& \text { missing_values }=\text { find }(\text { isnan }(y)) \text {; } \\
& \mathrm{w}(\text { missing_values })=0 \text {; } \\
& \mathrm{y}(\text { missing_values })=0 \text {; } \\
& \mathrm{W}=\operatorname{spdiags}(\mathrm{w}, 0, \text { length }(\mathrm{y}) \text {, leng- } \\
& \text { th(y)); \% Sparse matrix formed } \\
& \text { from diagonals. } \\
& \mathrm{D}=\operatorname{diff}(\operatorname{speye}(\operatorname{length}(\mathrm{y})), 3) ; \% \\
& \text { third order difference } \\
& \mathrm{z}=\left(\mathrm{W}+\text { lambda* } \mathrm{D}^{\prime *} \mathrm{D}\right) \backslash(\mathrm{w} . * \mathrm{y}) ; \% \\
& \text { Whittaker smoothing } \\
& \text { equation. }
\end{aligned}
$$

In the present study we used third-order differences and $\lambda=10,000$, for example. Figure 1 presents the fluctuating raw data for cow (1821), with her trend lines. The smoothing is not part of the model calculation; it is only for presenting the trend and comparing the model outputs with the NRC (2001) model. 